\title{
Presencia de duplicación 2p25.3 y síndrome de microdeleción 2q37.3 en un mismo individuo
}

\author{
Lina Johanna Moreno ${ }^{\mathrm{a}}$ - José María Satizábal ${ }^{\mathrm{b}}$ - Daniela Arturo-Terranovac
}

\begin{abstract}
Resumen: El estudio del cromosoma 2 en los seres humanos ha permitido reconocer que su alteración, basada en una localización específica, puede conducir a diversas enfermedades asociadas. Mediante la identificación fenotípica, sustentada en el estudio molecular de hibridación genómica comparativa y un estudio bioinformático posterior, se detectó la presencia de una duplicación patogénica en la región cromosómica 2p25.3p24.3, relacionada con la afección de 36 genes. Adicionalmente, se identificó una deleción patogénica en la citobanda 2q37.3, relacionada con la afección de 36 genes. El análisis bioinformático demostró interacciones entre genes que explican características sintomatológicas. Esta es la primera vez que se presentan estas dos variantes en un mismo individuo. Ambas alteraciones se han asociado con retraso psicomotor moderado, autismo, neurohipófisis ectópica, aracnodactilia, cardiopatía congénita y alteraciones cardiovasculares. Se ha propuesto que la mutación HDAC4 es la causante de la mayoría de las características del síndrome de microdeleción 2q37. El fenotipo clínico heterogéneo es el resultado del reordenamiento cromosómico encontrado, lo cual permite describir, interpretar y dar un tratamiento oportuno y dirigido a la paciente y la respectiva conserjería genética familiar. Finalmente, esta es la primera vez que se reporta este tipo específico de reordenamiento cromosómico.
\end{abstract}

Palabras clave: hibridación genómica comparativa; HDAC4; reordenamiento cromosómico

Fecha de recepción: 21 de noviembre de 2018 Fecha de aprobación: 30 de mayo de 2019

Cómo citar: Moreno Giraldo LJ, Satizabal Soto JM, Arturo Terranova D. Presencia de duplicación 2p25.3 y síndrome de microdeleción 2q37.3 en un mismo individuo. Revista Med 27(2): 75-86. Disponible en: https://revistas.unimilitar.edu.co/index.php/rmed/article/view/3784

a MD, Pediatra. M. Sc. Ciencias Biomédicas, énfasis en genética médica. Ph. D. (c). Adscrita a Universidad del Valle, Universidad Santiago de Cali, Universidad Libre (Cali) y al posgrado en Ciencias BiomédicasGenética Médica de la Universidad del Valle; perteneciente al Grupo de Investigación Enfermedades Congénitas del Metabolismo. Correo electrónico: linajohannamoreno@yahoo.es

b Bióloga, M. Sc. en Ciencias Biomédicas (e). Adscrita a la Universidad del Valle y perteneciente al Grupo de Investigación Enfermedades Congénitas del Metabolismo.

c MD, M. Sc., Ph. D. en Ciencias Biomédicas, énfasis en Genética Médica. Adscrito a Universidad del Valle, Universidad Santiago de Cali y al posgrado en Ciencias Biomédicas-Genética Médica de la Universidad del Valle; director del Grupo de Investigación Enfermedades Congénitas del Metabolismo. 


\title{
Presence of 2p25.3 Duplication and 2q37.3 Microdeletion Syndrome in the Same Individual
}

\begin{abstract}
The study of chromosome 2 in humans has allowed recognizing that its alteration, based on a specific location, can lead to various associated diseases. Through the phenotypic identification, supported by comparative genomic hybridization and subsequent bioinformatic analysis, the presence of a pathogenic duplication was detected in the chromosomal region 2p25.3p24.3 affecting 36 genes. Additionally, a pathogenic deletion was identified in cytoband 2937.3 affecting 36 genes. The bioinformatic analysis showed interactions among genes that explain symptomatic characteristics. This is the first time that these two variants are present in the same individual. Both disorders have been associated with moderate psychomotor retardation, autism, ectopic neurohypophysis, arachnodactyly, congenital heart disease, and cardiovascular disorders. The HDAC4 mutation has been suggested to cause most of the features of 2 q37 microdeletion syndrome. The heterogeneous clinical phenotype derives from the chromosomal rearrangement found, which allows describing, interpreting, and providing the patient with timely targeted treatment and the respective family genetic counseling. Finally, this specific type of chromosomal rearrangement has been reported for the first time.
\end{abstract}

Keywords: Comparative genomic hybridization; HDAC4; chromosomal rearrangement

\section{Presença de duplicação 2p25.3 e síndrome da microdeleção 2p25.3 no mesmo indivíduo}

Resumo: $\mathrm{O}$ estudo do cromossomo 2 em seres humanos nos permitiu reconhecer que sua alteração, com base em uma localização específica, pode levar a diversas doenças associadas. Por meio da identificação fenotípica, apoiada no estudo molecular da hibridação genômica comparativa e em um estudo bioinformático posterior, foi detectada a presença de uma duplicação patogênica na região cromossômica 2p25.3p24.3, relacionada a 36 genes afetados. Além disso, uma deleção patogênica foi identificada na citobanda 2q37.3, relacionada a 36 genes afetados. A análise bioinformática mostrou interações entre genes que explicam características sintomáticas. É a primeira vez que essas duas variantes são apresentadas no mesmo indivíduo. Ambos os distúrbios têm sido associados a retardo psicomotor moderado, autismo, neuro-hipófise ectópica, aracnodactilia, doenças cardíacas congênitas e distúrbios cardiovasculares. Propõe-se que a mutação HDAC4 é a causa da maioria das características da síndrome de microdeleção 2q37. O fenótipo clínico heterogêneo é o resultado do rearranjo cromossômico encontrado, que permite descrever, interpretar e oferecer um tratamento oportuno direcionado ao paciente e ao respectivo aconselhamento genético familiar. Finalmente, também é a primeira vez que esse tipo específico de rearranjo cromossômico é relatado.

Palavras-chave: hibridação genômica comparativa; HDAC4; rearranjo cromossômico 


\section{Introducción}

En los humanos, el cromosoma 2 es el segundo más grande, después del cromosoma 1 que representa, aproximadamente, el 8,0\% del material genético. El cromosoma 2 posee una longitud de $242193529 \mathrm{pb}$, un total de 1301 genes codificantes ,1578 genes no codificantes y 1075 pseudogenes (1). Se caracteriza por ser un cromosoma autosómico $\mathrm{y}$, por tanto, no influye en la determinación del sexo los individuos.

El mapeo del cromosoma 2 ha permitido reconocer que su alteración, tanto duplicación como deleción, puede conducir a una serie de enfermedades asociadas (2); mientras tanto, el análisis genético de dichas enfermedades puede tener un valor pronóstico importante, así como la realización adecuada del consejo genético. Las enfermedades asociadas al cromosoma 2 pueden dividirse con base en su localización, es decir, localizadas en el brazo corto o en el brazo largo, haciendo referencia a los locus donde se encuentran.

Una de las enfermedades asociadas al cromosoma 2 es el síndrome $2 \mathrm{p} 25$, un trastorno raro y clínicamente heterogéneo, que se manifiesta por material genético adicional en porciones de tamaño variable del brazo corto de este cromosoma. Las características comunes de esta patología incluyen retraso del desarrollo, características dismórficas craneofaciales (incluido hipertelorismo y frente prominente) y malformaciones cardiovasculares. La duplicación 2p25 se había informado hasta 2016 solo en diez pacientes, como una aberración aislada de la región terminal de $2 \mathrm{p}$ (3).

El síndrome de microdeleción 2q37 es también una enfermedad asociada al cromosoma 2, que puede afectar muchos órganos del cuerpo. Esta enfermedad es causada por una deleción del material genético de la región específica q37 en el brazo largo (q) de este cromosoma. La deleción ocurre cerca del final del cromosoma (deleción terminal) en el lugar designado 2q37 (4). Hasta 2013, se habían reportado cerca de 60 casos de deleción o monosomía $2 \mathrm{q} 37$, resultantes de translocaciones desequilibradas. La variabilidad significativa en la presentación clínica es evidente, pero casi todos los pacientes tienen algún grado de retraso mental y dismorfia facial. Las anomalías congénitas del corazón, con respecto a este síndrome, están presentes en aproximadamente el $20 \%$ de los pacientes. La mayoría de las personas con este síndrome tienen una deleción de novo, lo que significa que no es heredado y que sus padres tienen cromosomas normales (5). Esta deleción cromosómica ocurre como un acontecimiento al azar, durante la formación de las células reproductoras o durante el desarrollo fetal temprano. Aproximadamente en $5 \%$ de los casos publicados, los pacientes heredan la deleción de un padre portador de una translocación equilibrada.

La presencia de malformaciones congénitas múltiples y su gravedad son los factores más importantes para el pronóstico y para determinar la esperanza de vida de los pacientes. Los reportes de pacientes adultos con estos síndromes son pocos; por lo que se hace necesario conocer más sobre la historia natural de la enfermedad para suministrar la atención integral transdisciplinaria adecuada, para los pacientes afectados por estos defectos genéticos y sus familias (6).

Esta es la primera vez que se describe un reordenamiento cromosómico con una duplicación (2p25.3) y una microdeleción (2q37.3.) en un mismo individuo. De allí la importancia de su caracterización fenotípica, descripción sindrómica y análisis genómico bioinformático, para poder instaurar tratamientos dirigidos que impacten en la morbilidad y mortalidad de los pacientes y para poder realizar la consejería genética.

\section{Metodología}

Se determinaron las características fenotípicas de interés de una paciente, mediante las cuales se pudiera llegar a un diagnóstico preciso. Posteriormente, se hizo la cuantificación de actividad enzimática para $\beta$-galactosidasa, galactosa-6-sulfato sulfatasa y arilsulfatasa $B$, por métodos fluorométricos, además de realizar la cuantificación de hormonas TSH, T4L, TGO-AST y TGP-ALT en plasma.

Se llevó a cabo un estudio molecular de hibridación genómica comparativa (HGC), basado en matrices que incluyen 180000 oligonucleótidos o sondas, diseñadas con la secuencia complementaria 
a las 180000 mutaciones más frecuentes del genoma, con el objetivo de indagar los 1714 genes que presentan mayor compromiso con el desarrollo de enfermedades genéticas, 700 micro-RNA y todo el genoma mitocondrial. Esta técnica permite detectar la pérdida de un número variable de copias (deleción), ganancia de números variables de copias (duplicación) o establecer el número normal de copias.

Finalmente, se realizó un estudio genómico bioinformático utilizando las herramientas Clinvar, Genecards, Online Mendelian Inheritance in Man (омім) y Human Gene Mutation Database (HGMD) con el fin de identificar las funciones descritas de los genes involucrados y se evaluaron las redes de expresión genómicas entre los genes afectados, utilizando el software sTITCH 5 (http:// stitch.embl.de/).

\section{Resultados}

En la evaluación realizada a una paciente de sexo femenino, de 18 años, se encontró una talla de 145 $\mathrm{cm}$ (desviación estándar [DE]: 21,21 cm), $36 \mathrm{~kg}$ de peso (DE: $12 \mathrm{Kg}$ ) y 17, $12 \mathrm{~kg} / \mathrm{m}^{2}$ de índice de masa corporal (IMC), lo que indica delgadez, según la resolución colombiana 2465 de 2016.

El análisis de exploración física indicó presencia de facies dismórfica, con cara abotagada y cuello corto; además se reportó retraso psicomotor moderado y autismo, microadenoma hipofisiario con engrosamiento fusiforme del infundíbulo de aproximadamente $4,7 \times 2,5 \mathrm{~mm}$, que corresponde a neurohipófisis ectópica, observada en la resonancia nuclear de base de cráneo. Asimismo, se evidenció agenesia renal unilateral izquierda, aracnodactilia en manos y pies, además de la ausencia de ovario izquierdo, uterodesviación izquierda y afecciones por cardiopatías.

Al realizar la cuantificación por métodos fluorométricos de actividad enzimática para $\beta$-galactosidasa, galactosa-6-sulfato sulfatasa y arilsulfatasa $B$ a partir de leucocitos, se observó normalidad en los resultados enzimáticos, pues se encontraban dentro los valores de referencias normales. Asimismo, se cuantificaron las hormonas TSH, T4L, TGOAST y TGP-ALT plasmáticas, lo cual también arrojó resultados normales.

El estudio molecular de deleciones y duplicaciones por la técnica de hibridación genómica comparativa (HGC) determinó una duplicación patogénica en la región cromosómica 2p25.3p24.3, con coordenadas genómicas Chr2:17019_16364856 de $16,34 \mathrm{Mb}$, relacionada con la afección de 36 genes (Tabla 1). Adicionalmente se identificó una deleción patogénica en la citobanda 2q37.3, coordenadas genómicas Chr2: 238043371_243040276 de 4,99 Mb; deleción relacionada con la afección de 36 genes (Tabla 2).

Tabla 1. Genes afectados por la duplicación 2p25.3p24.3

\begin{tabular}{|c|c|c|c|}
\hline $\begin{array}{c}\text { Localización } \\
\text { cromosómica }\end{array}$ & $\begin{array}{c}\text { Tipo } \\
\text { de CNV }\end{array}$ & $\begin{array}{c}\text { Clasificación } \\
\text { CNV }\end{array}$ & Genes afectados \\
\hline $2 p 25.3 p 24.3$ & Duplicación & Patogénica & $\begin{array}{c}\text { ACP1, TMEM18, TPO, PXDN, MYT1L, TSSC1, TRAPPC12, ADI1, COLEC11, ALLC, } \\
\text { SOX11, CMPK2, RSAD2, ID2, KIDINS220, MBOAT2, ITGB1BPT, ADAM17, } \\
\text { GRHL1, K1F11, RRM2, HPCAL1, ODCI, NOL10, PDIA6, KCNFL1, ROCK2, GREB1, } \\
\text { NTSR2, LPIN1, FAM84A, NBA5, DDX1, MYCNUT, MYCNOS, MYCN, GACAT }\end{array}$ \\
\hline
\end{tabular}

Tabla 2. Genes afectados por la deleción 2 q37.3

\begin{tabular}{l}
$\begin{array}{l}\text { Localización } \\
\text { cromosómica }\end{array}$ \\
\hline
\end{tabular}


Esta es la primera vez que se reporta la aparición de estas dos variantes en un mismo individuo, en el número de copias simultáneamente, por lo que se describieron las alteraciones por separado para llegar a un cuadro clínico que pudiera explicar el fenotipo de la paciente y su etiología molecular.

La identificación de las funciones descritas de los genes involucrados en la duplicación 2p25.3p24.3 (Tabla 3) y la deleción en 2q37.3
(Tabla 4) mostró la afección de genes implicados en la regulación de procesos celulares, como el crecimiento celular, la senescencia, la diferenciación, la apoptosis, la angiogénesis y la transformación neoplásica, así como múltiples procesos asociados a factores de crecimiento y afecciones en los patrones circadianos, que resultan afectados por estas duplicaciones-deleciones.

Tabla 3. Funciones descritas para genes afectados por la duplicación 2p25.3p24.3

\begin{tabular}{|c|c|c|c|c|}
\hline GEN & $\begin{array}{l}\text { Número } \\
\text { OMIN }\end{array}$ & Nombre del gen & $\begin{array}{l}\text { Localización } \\
\text { cromosómica }\end{array}$ & Función \\
\hline ACP1 & *171500 & Acid phosphatase 1 & $2 \mathrm{p} 25.3$ & $\begin{array}{l}\text { Actúa sobre proteínas fosforiladas en } \\
\text { tirosina, arilfosfatos de bajo peso molecular } \\
\text { y acilfosfatos, naturales y sintéticos. }\end{array}$ \\
\hline TMEM18 & *613220 & $\begin{array}{l}\text { Transmembrane } \\
\text { protein } 18 \\
\end{array}$ & $2 \mathrm{p} 25.3$ & $\begin{array}{l}\text { Afecta los niveles de energía a través de } \\
\text { la señalización de insulina y glucagón. }\end{array}$ \\
\hline TPO & *606765 & Thyroid peroxidase & $2 \mathrm{p} 25.3$ & $\begin{array}{l}\text { Yodación de los residuos de tirosina, para generar } \\
\text { las hormonas tiroideas, tiroxina y triyodotironina. }\end{array}$ \\
\hline PXDN & *605158 & Peroxidasin & $2 \mathrm{p} 25.3$ & $\begin{array}{c}\text { Formación de la matriz extracelular y puede } \\
\text { funcionar en la respuesta fibrogénica fisiológica } \\
\text { y patológica en el riñón fibrótico. }\end{array}$ \\
\hline MYT1L & *613084 & $\begin{array}{l}\text { Myelin transcription } \\
\text { factor 1-like }\end{array}$ & $2 \mathrm{p} 25.3$ & $\begin{array}{l}\text { Funcionan en el sistema nervioso } \\
\text { central de los mamíferos en desarrollo. }\end{array}$ \\
\hline Tssc1 & *608998 & $\begin{array}{l}\text { Earp complex and } \\
\text { garp complex } \\
\text { interacting protein } 1\end{array}$ & $2 \mathrm{p} 25.3$ & Supresión de tumores. \\
\hline TRAPPC12 & *614139 & $\begin{array}{l}\text { Trafficking protein } \\
\text { particle complex } 12\end{array}$ & $2 \mathrm{p} 25.3$ & $\begin{array}{l}\text { Ensamblaje del cinetocoro y estabilidad; controla } \\
\text { el reclutamiento de CENPE para los cinetocoros. }\end{array}$ \\
\hline ADI1 & *613400 & $\begin{array}{l}\text { Acireductone } \\
\text { dioxygenase } 1\end{array}$ & $2 p 25.3$ & Regula el procesamiento de ARNM en el núcleo. \\
\hline COLEC11 & *612502 & Collectin 11 & $2 p 25.3$ & Migración de las células de la cresta neural. \\
\hline ALLC & *612396 & Allantoicase & $2 p 25.3$ & Soporte en la degradación del ácido úrico. \\
\hline sox11 & *600898 & Sry-box 11 & $2 \mathrm{p} 25.3$ & $\begin{array}{l}\text { Actores de transcripción involucrados en la } \\
\text { regulación del desarrollo embrionario } \\
\text { y en la determinación del destino celular. }\end{array}$ \\
\hline CMPK2 & *611787 & $\begin{array}{l}\text { Cytidine/uridine } \\
\text { monophosphate } \\
\text { kinase } 2\end{array}$ & $2 \mathrm{p} 25.3$ & $\begin{array}{l}\text { Participa en la síntesis de DUTP } \\
\text { y DCTP en las mitocondrias. }\end{array}$ \\
\hline RSAD2 & *607810 & $\begin{array}{l}\text { Radical S-adenosyl } \\
\text { methionine domain- } \\
\text { containing protein } 2\end{array}$ & $2 p 25.2$ & $\begin{array}{l}\text { Promueve la producción dependiente de TLR7 } \\
\text { y TLR9 de la producción de IFN- } \beta \text { en células } \\
\text { plasmocitoides dendríticas (pdc) al facilitar } \\
\text { la ubiquitinación ligada a Lys-63 de IRAK1. } \\
\text { Juega un papel en la activación y } \\
\text { diferenciación de las células T CD4. }\end{array}$ \\
\hline ID2 & *600386 & $\begin{array}{l}\text { Inhibitor of DNA } \\
\text { binding-1 }\end{array}$ & $2 p 25.1$ & $\begin{array}{l}\text { Implicado en la regulación de una variedad de } \\
\text { procesos celulares, incluido el crecimiento celular, } \\
\text { la senescencia, la diferenciación, la apoptosis, la } \\
\text { angiogénesis y la transformación neoplásica. }\end{array}$ \\
\hline
\end{tabular}




\begin{tabular}{|c|c|c|c|c|}
\hline GEN & $\begin{array}{l}\text { Número } \\
\text { OMIN }\end{array}$ & Nombre del gen & $\begin{array}{l}\text { Localización } \\
\text { cromosómica }\end{array}$ & Función \\
\hline KIDINS220 & *615759 & $\begin{array}{l}\text { Kinase } D \text {-interacting } \\
\text { substrate }\end{array}$ & $2 \mathrm{p} 25.1$ & $\begin{array}{l}\text { Desempeña un papel importante en la regulación } \\
\text { de la transducción de señales postsinápticas a } \\
\text { través de la localización mediada por sintrofina de } \\
\text { las tirosina quinasas receptoras, como la EPHA4. }\end{array}$ \\
\hline MBOAT2 & *611949 & $\begin{array}{l}\text { Membrane-bound } \\
\text { 0-acyltransferase } \\
\text { domain-containing } \\
\text { protein } 2 \\
\end{array}$ & $2 \mathrm{p} 25.1$ & $\begin{array}{c}\text { Cataliza también la acilación del ácido lisofosfatídico } \\
\text { en ácido fosfatídico (actividad lpaat). }\end{array}$ \\
\hline ADAM17 & *603639 & $\begin{array}{l}\text { A disintegrin and } \\
\text { metalloproteinase } \\
\text { domain } 17\end{array}$ & $2 p 25.1$ & $\begin{array}{c}\text { Funciona en el procesamiento de numerosos } \\
\text { sustratos, incluidas las proteínas de adhesión } \\
\text { celular, los receptores de citoquinas y factores } \\
\text { de crecimiento y los ligandos del receptor del } \\
\text { factor de crecimiento epidérmico. }\end{array}$ \\
\hline GRHL1 & *609786 & $\begin{array}{l}\text { Grainyhead like } \\
\text { transcription factor } 1\end{array}$ & $2 p 25.1$ & Factor de transcripción durante el desarrollo. \\
\hline RRM2 & *180390 & $\begin{array}{l}\text { Ribonucleotide reductase } \\
\text { regulatory subunit M2 }\end{array}$ & $2 p 25.1$ & $\begin{array}{c}\text { Proporciona los precursores necesarios para } \\
\text { la síntesis de ADN. Cataliza la biosíntesis } \\
\text { de desoxirribonucleótidos a partir de los } \\
\text { ribonucleótidos correspondientes. }\end{array}$ \\
\hline HPCAL1 & *600207 & Hippocalcin like 1 & $2 \mathrm{p} 25.1$ & $\begin{array}{l}\text { Participar en la regulación dependiente de } \\
\text { calcio de la fosforilación de rodopsina. }\end{array}$ \\
\hline NOL10 & *616197 & Nucleolar protein & $2 \mathrm{p} 25.1$ & Ensamblaje de partículas ribosómicas. \\
\hline PDIA6 & *611099 & $\begin{array}{l}\text { Protein disulfide } \\
\text { isomerase family } \\
\text { A member } 6\end{array}$ & $2 \mathrm{p} 25.1$ & $\begin{array}{l}\text { Chaperona que inhibe la agregación de proteínas } \\
\text { mal plegadas. Regula negativamente la respuesta } \\
\text { de la proteína desplegada. }\end{array}$ \\
\hline ROCK2 & *604002 & $\begin{array}{l}\text { Rho associated coiled- } \\
\text { coil containing protein } \\
\text { kinase } 2 \\
\end{array}$ & $2 p 25.1$ & $\begin{array}{c}\text { Regula la citocinesis, la contracción del músculo } \\
\text { liso, la formación de fibras de estrés de actina } \\
\text { y las adherencias focales. }\end{array}$ \\
\hline GREB1 & *611736 & $\begin{array}{l}\text { Growth regulating } \\
\text { estrogen receptor } \\
\text { binding } 1\end{array}$ & $2 p 25.1$ & $\begin{array}{l}\text { Proliferación celular estimulada por estrógenos. } \\
\text { Actúa como un regulador del crecimiento del } \\
\text { cáncer dependiente de hormonas en los cánceres } \\
\text { de mama y próstata. }\end{array}$ \\
\hline NTSR2 & *605538 & Neurotensin receptor 2 & $2 p 25.1$ & $\begin{array}{l}\text { Se asocia con proteínas G que activan un sistema } \\
\text { de segundo mensajero de fosfatidilinositol y calcio. }\end{array}$ \\
\hline LPIN1 & *605518 & Lipin 1 & $2 p 25.1$ & $\begin{array}{l}\text { Control del metabolismo de los ácidos grasos } \\
\text { en diferentes niveles. Actúa como una enzima } \\
\text { fosfatasa dependiente de magnesio que cataliza } \\
\text { la conversión de ácido fosfatídico a diacilglicerol. }\end{array}$ \\
\hline FAM84A & *611234 & $\begin{array}{l}\text { Family with sequence } \\
\text { similarity } 84 \text { member A }\end{array}$ & $2 p 24.3$ & Desempeña un papel en la migración celular. \\
\hline DDX1 & *601257 & DEAD-box helicase 1 & $2 p 24.3$ & $\begin{array}{l}\text { Este gen codifica una proteína de DEAD-box } \\
\text { de función desconocida. }\end{array}$ \\
\hline MYCNUT & *615968 & MYCN upstream transcript & $2 p 24.3$ & Control de neuroblastomas. \\
\hline MYCNOS & *605374 & MYCN opposite strand & $2 p 24.3$ & $\begin{array}{l}\text { Regula la estabilidad de MYCN en células } \\
\text { de neuroblastoma mediante la inhibición de la } \\
\text { fosforilación de MYCN mediada por GSK3B. }\end{array}$ \\
\hline MYCN & *164840 & $\begin{array}{l}\text { MYCN proto-oncogene, } \\
\text { BHLH transcription factor }\end{array}$ & $2 p 24.3$ & $\begin{array}{l}\text { Regularmente regula la transcripción de } \\
\text { MYCNOS en células de neuroblastoma. }\end{array}$ \\
\hline
\end{tabular}


Tabla 4. Funciones descritas para genes afectados por la deleción en 2q37.3

\begin{tabular}{|c|c|c|c|c|}
\hline Gen & $\begin{array}{l}\text { Número } \\
\text { OMIN }\end{array}$ & Nombre del gen & $\begin{array}{l}\text { Localización } \\
\text { cromosómica }\end{array}$ & Función \\
\hline COL6A3 & *120220 & $\begin{array}{l}\text { Collagen type vi } \\
\text { alpha } 3 \text { chain }\end{array}$ & $2 q 37.3$ & $\begin{array}{c}\text { Colágeno tipo vi, alfa } 3 \text { (300 kDa), } \\
\text { microfibrilar, supuestamente gen } \\
\text { diana c-Myc regulado por disminución. }\end{array}$ \\
\hline MLPH & *606526 & Melanophilin & $2 q 37.3$ & $\begin{array}{c}\text { Implicada en el transporte de } \\
\text { melanosomas. Sirve como enlace } \\
\text { entre RAB27A unido a melanosoma } \\
\text { y la proteína motora mY05A. }\end{array}$ \\
\hline RAB17 & *602206 & Ras-associated protein & $2 q 37.3$ & $\begin{array}{l}\text { Controla el tráfico de membrana a } \\
\text { través de endosomas apical de reciclaje. }\end{array}$ \\
\hline LRRFIP1 & *603256 & $\begin{array}{l}\text { LRR binding FLII } \\
\text { interacting protein } 1\end{array}$ & $2 q 37.3$ & $\begin{array}{l}\text { Regula la expresión de TNF, EGFR y } \\
\text { PDGFA. Puede controlar la proliferación } \\
\text { de las células musculares lisas. }\end{array}$ \\
\hline RAMP1 & *605153 & $\begin{array}{l}\text { Receptor activity } \\
\text { modifying protein } 1\end{array}$ & $2 q 37.3$ & $\begin{array}{l}\text { Actúa como un receptor para el péptido } \\
\text { relacionado con el gen de la calcitonina. }\end{array}$ \\
\hline SCLY & *611056 & Selenocysteine lyase & $2 q 37.3$ & $\begin{array}{c}\text { Cataliza la descomposición de } \\
\text { L-selenocisteína a L-alanina y } \\
\text { selenio elemental. }\end{array}$ \\
\hline FAM132B & *615099 & Erythroferrone & $2 q 37.3$ & $\begin{array}{l}\text { Hormona reguladora del hierro que } \\
\text { actúa como un regulador eritroide. }\end{array}$ \\
\hline HES6 & *610331 & $\begin{array}{l}\text { Hes family BHLH } \\
\text { transcription factor } 6\end{array}$ & $2 q 37.3$ & Promueve la diferenciación celular. \\
\hline PER2 & *603426 & $\begin{array}{l}\text { Period circadian } \\
\text { regulator } 2 \\
\end{array}$ & $2 q 37.3$ & $\begin{array}{l}\text { Se expresa en un patrón circadiano } \\
\text { en el núcleo supraquiasmático. }\end{array}$ \\
\hline TRAF3IP1 & *607380 & $\begin{array}{l}\text { TRAF3 interacting } \\
\text { protein } 1\end{array}$ & $2 q 37.3$ & $\begin{array}{l}\text { Participa en la supresión de la } \\
\text { fosforilación de STAT6 inducida por IL-13, } \\
\text { la actividad transcripcional y la unión } \\
\text { al ADN. Recluta TRAF3 y DISC1 a los } \\
\text { microtúbulos. Participa en el desarrollo } \\
\text { renal y en la morfogénesis epitelial. }\end{array}$ \\
\hline ASB1 & *605758 & $\begin{array}{l}\text { Ankyrin repeat and } \\
\text { socs box containing } 1\end{array}$ & $2 q 37.3$ & $\begin{array}{l}\text { degradación proteasomal } \\
\text { de las proteínas diana. }\end{array}$ \\
\hline TWIST2 & *607556 & $\begin{array}{l}\text { Twist family BHLH } \\
\text { transcription factor } 2\end{array}$ & $2 q 37.3$ & $\begin{array}{l}\text { Participa en el almacenamiento } \\
\text { de glucógeno posnatal y el } \\
\text { metabolismo energético. }\end{array}$ \\
\hline HDAC4 & *605314 & Histone deacetylase 4 & $2 q 37.3$ & $\begin{array}{l}\text { Desempeña un papel importante } \\
\text { en la regulación transcripcional, } \\
\text { la progresión del ciclo celular y } \\
\text { los eventos de desarrollo. }\end{array}$ \\
\hline GPC1 & *600395 & Glypican 1 & $2 q 37.3$ & $\begin{array}{c}\text { Participa en la mielinización } \\
\text { de células de Schwann. }\end{array}$ \\
\hline MIR149 & *615209 & Micro-RNA 149 & $2 q 37.3$ & Supresor de tumores. \\
\hline RNPEPL1 & *605287 & $\begin{array}{l}\text { Arginyl aminopeptidase } \\
\text { like } 1\end{array}$ & $2 q 37.3$ & $\begin{array}{c}\text { Liberación de aminoácidos } \mathrm{N} \text {-terminales, } \\
\text { preferentemente metionina, } \\
\text { a partir de péptidos y arilamidas. }\end{array}$ \\
\hline CAPN10 & *605286 & Calpain 10 & $2 q 37.3$ & $\begin{array}{c}\text { Captación de glucosa } \\
\text { estimulada por la insulina. }\end{array}$ \\
\hline GPR35 & *602646 & $\begin{array}{l}\text { G protein-coupled } \\
\text { receptor } 35\end{array}$ & $2 q 37.3$ & $\begin{array}{l}\text { Actúa como un receptor } \\
\text { para el ácido kinurénico. }\end{array}$ \\
\hline
\end{tabular}




\begin{tabular}{|c|c|c|c|c|}
\hline Gen & $\begin{array}{l}\text { Número } \\
\text { OMIN }\end{array}$ & Nombre del gen & $\begin{array}{l}\text { Localización } \\
\text { cromosómica }\end{array}$ & Función \\
\hline$A Q P 12 A$ & *609789 & Aquaporin $12 \mathrm{~A}$ & $2 q 37.3$ & $\begin{array}{l}\text { Facilitan el transporte de agua } \\
\text { y pequeños solutos neutros a } \\
\text { través de las membranas celulares. }\end{array}$ \\
\hline KIF1A & *601255 & $\begin{array}{l}\text { Kinesin family member } \\
1^{\mathrm{a}}\end{array}$ & $2 q 37.3$ & $\begin{array}{l}\text { Motor para el transporte axonal } \\
\text { anterógrado de precursores de } \\
\text { vesículas sinápticas. }\end{array}$ \\
\hline AGXT & *604285 & $\begin{array}{c}\text { Alanine-glyoxylate and } \\
\text { serine- } \\
\text { pyruvate } \\
\text { aminotransferase }\end{array}$ & $2 q 37.3$ & Capacidad de dimerizar. \\
\hline SNED1 & *616634 & $\begin{array}{l}\text { Sushi, nidogen and EGF } \\
\text { like domains } 1\end{array}$ & $2 q 37.3$ & $\begin{array}{l}\text { Interactúa con la somatostatina, la } \\
\text { espermidina sintasa y тMEM132C. }\end{array}$ \\
\hline PASK & *607505 & $\begin{array}{l}\text { PAS domain containing } \\
\text { serine/threonine kinase }\end{array}$ & $2 q 37.3$ & $\begin{array}{l}\text { Sensor involucrado en la homeostasis } \\
\text { de la energía: regula la síntesis de la } \\
\text { glucógeno sintasa mediante la } \\
\text { mediación de la fosforilación de GYs1. }\end{array}$ \\
\hline PPP1R7 & *602877 & $\begin{array}{l}\text { Protein Phosphatase } 1 \\
\text { Regulatory Subunit } 7\end{array}$ & $2 q 37.3$ & $\begin{array}{c}\text { Subunidad reguladora de } \\
\text { la proteína fosfatasa } 1 .\end{array}$ \\
\hline HDLBP & *142695 & $\begin{array}{l}\text { High density lipoprotein } \\
\text { binding protein }\end{array}$ & $2 q 37.3$ & $\begin{array}{c}\text { Metabolismo de los esteroles celulares. } \\
\text { Puede funcionar para proteger a las células de la } \\
\text { acumulación excesiva } \\
\text { de colesterol. }\end{array}$ \\
\hline SEPT2 & *601506 & Septin 2 & $2 q 37.3$ & $\begin{array}{c}\text { Requerido para la organización normal } \\
\text { del citoesqueleto de actina. Desempeña } \\
\text { un papel en la biogénesis del epitelio } \\
\text { al mantener los microtúbulos poliglutamilados, } \\
\text { con lo cual facilita el } \\
\text { transporte eficiente de vesículas e } \\
\text { impide la unión de MAP4 a la tubulina. }\end{array}$ \\
\hline STK25 & *602255 & $\begin{array}{c}\text { Serine/threonine kinase } \\
25\end{array}$ & $2 q 37.3$ & $\begin{array}{c}\text { Regula los eventos de transporte } \\
\text { de proteínas, la adhesión celular y } \\
\text { los complejos de polaridad importantes } \\
\text { para la migración celular. }\end{array}$ \\
\hline THAP & *612533 & $\begin{array}{l}\text { THAP domain containing } \\
4\end{array}$ & $2 q 37.3$ & $\begin{array}{c}\text { Actividad de homodimerización } \\
\text { de proteínas. }\end{array}$ \\
\hline DTYMK & *188345 & $\begin{array}{l}\text { Deoxythymidylate } \\
\text { kinase }\end{array}$ & $2 q 37.3$ & $\begin{array}{l}\text { Actividad de homodimerización } \\
\text { de proteínas. }\end{array}$ \\
\hline ING5 & *608525 & $\begin{array}{l}\text { Inhibitor of growth } \\
\text { family member } 5\end{array}$ & $2 q 37.3$ & $\begin{array}{c}\text { Actividad de acetiltransferasa } \\
\text { específica de histona } \mathrm{H} 4 \text {. }\end{array}$ \\
\hline NEU4 & *608527 & Neuraminidase 4 & $2 q 37.3$ & $\begin{array}{l}\text { Catabolismo lisosomal de } \\
\text { glicoconjugados sialilados. }\end{array}$ \\
\hline PDCD1 & *600244 & $\begin{array}{l}\text { Programmed cell } \\
\text { death } 1\end{array}$ & $2 q 37.3$ & $\begin{array}{c}\text { Receptor inhibitorio de la superficie } \\
\text { celular, involucrado en la regulación } \\
\text { de la función de las células T durante } \\
\text { la inmunidad y la tolerancia. }\end{array}$ \\
\hline
\end{tabular}


Las redes de expresión génicas, usadas para determinar las interrelaciones metabólicas de las proteínas expresadas con otras moléculas pequeñas, mostró procesos biológicos afectados por la duplicación en la citobanda 2p25.3p24.3 (Figura 1a) como la morfogénesis de lámina epitelial, el empalme de ARNt, a través de escisión endonucleolítica y procesos biosintéticos desoxirribunucleótidos. Además, las funciones moleculares como la reducción en la actividad del difosfato ribonucleótido también se vieron alteradas.

De otro lado, la red de interacción entre los genes afectados por la deleción en la 2q37.3 (Figura 1b) permitió observar afecciones relacionadas con procesos biológicos, como la regulación circadiana de los genes de expresión, regulación del transporte de L-glutamato, muerte celular programada, mediada por peróxido de hidrógeno. Funciones moleculares como la actividad fotoliasa del ADN y actividad en los receptores de calcitoninas.
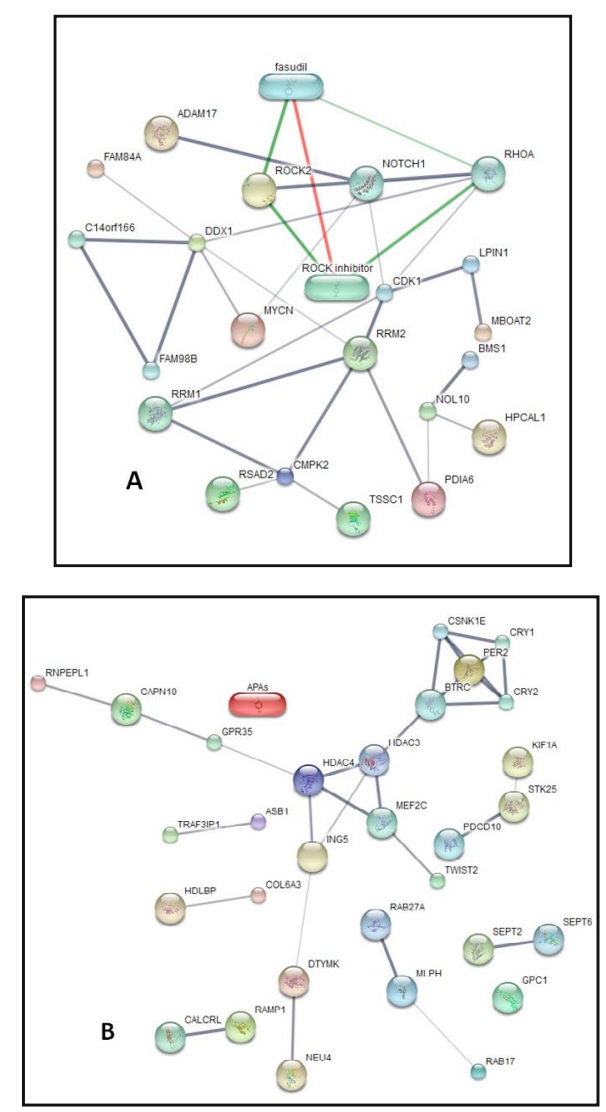

Figura 1. Redes de expresión génica asociadas a duplicación 2p25.3p24.3 (a) y deleción 2q37.3 (b).
Finalmente, la red de interacción que relacionaba los genes afectados tanto por duplicación como por deleción (Figura 2), mostró una interacción asociada entre los dos tipos de mutaciones e implican ambos tipos de genes en una sola ruta de afecciones. Se observaron alteraciones en procesos biológicos tales como rutas de desoxirribonucleótidos, regulación del ritmo circadiano y regulación del transporte de L-glutamato. En cuanto a las funciones moleculares, se observaron alteraciones en la actividad fotoliasa del ADN, actividad quinasa timidilato, actividad en los receptores calcitoninos. Las rutas que se vieron más afectadas por las interacciones génicas fueron aquellas relacionadas con el ritmo circadiano.

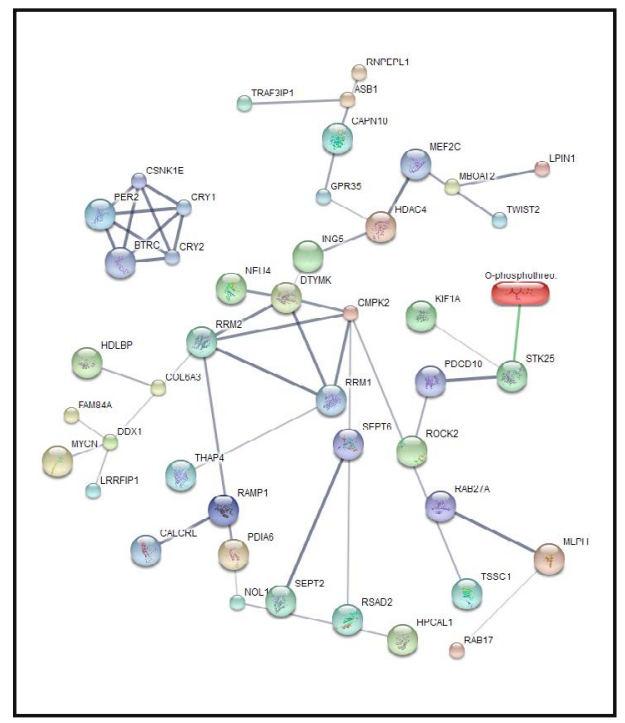

Figura 2. Red de expresión de genes implicados tanto en duplicación 2p25.3 como en la microdeleción 2q37.

\section{Discusión}

El síndrome de duplicación de la citobanda 2p25.3 se ha asociado con diferentes fenotipos del neurodesarrollo, como retardo en el desarrollo psicomotor y del lenguaje, discapacidad intelectual y autismo; además de rasgos faciales dismórficos (7). Estudios realizados por Buizer-Voskamp y sus colaboradores en 2011 sugirieron que las modificaciones en el locus 2p25.3 dan lugar a diferentes fenotipos del neurodesarrollo (8). 
En 2008, Vrijenhoek y su equipo fueron los primeros en informar de dos pacientes con esquizofrenia y la presencia de microduplicaciones que interrumpieron el gen MYT1L, en la citobanda 2p25.3 (9). Posteriormente, informaron de dos pacientes más con esquizofrenia de inicio en la niñez (cos) que también presentaban microduplicaciones que afectaban los genes MYT1L y PXDN (10). Asimismo, Lee y sus colaboradores, en 2012, reportaron dos pacientes con cos que portaban las microduplicaciones que afectaban los mismos genes evaluados, ello indicaba una fuerte evidencia de asociación entre microduplicaciones de tamaño variable que involucran genes como MYT1L y la esquizofrenia (11).

Adicionalmente, en 2016, investigaciones realizadas por Sperry y su equipo reportaron el caso de una paciente de 15 años con características clínicas del síndrome de Charge y una ganancia de novo de 6,5 Mb de material genómico en 2p25.3. La región duplicada contenía 24 genes, incluido el gen del factor de transcripción temprano y ampliamente expresado sox11.

Actualmente, en bases de datos de CNV poblacionales como Database of Genomics Variants (DGV), no se encuentra reporte de duplicaciones de tamaño similar. Sin embargo, en bases de datos que incluyen variantes patogénicas como Decipher, se han reportado duplicaciones de tamaño similar a la identificada en este paciente, clasificadas como patogénicas y relacionadas con retardo en el desarrollo psicomotor.

De otro lado, la deleción encontrada en la citobanda 2q37.3 se asoció con el síndrome de microdeleción $2 \mathrm{q} 37$, también conocido como síndrome de braquidactilia, asociado con anomalías cognitivas y de comportamiento, incluyendo trastornos del sueño.

Los afectados de esta deleción desarrollan talla baja, hipotonía, braquidactilia tipo E, dismorfias faciales como frente prominente con cejas arqueadas, ojos hundidos, puente nasal deprimido, labio superior fino y, más raramente, defectos cardiacos, convulsiones e incluso tumor de Wilms (5). También se ha reportado que, aproximadamente, un tercio de los afectados con síndrome de microdeleción $2 q 37$ tiene características similares al autismo o autismo, que muestran una variación significativa entre los individuos. No obstante, ningún fenotipo conductual parece ser específico del síndrome de microdeleción 2q37 (12).

La deleción encontrada en la paciente evaluada hace parte del grupo de deleciones pequeñas ocurridas en dicha región cromosómica; lo anterior, debido a que la deleción telomérica más grande informada en la región cromosómica 2q37 es de aproximadamente $10 \mathrm{Mb}$, mientras que la más pequeña es con frecuencia de alrededor de 3 a $4 \mathrm{Mb}$ (13).

Es muy probable que la eliminación de los genes en esta región cromosómica sea el defecto genético que se sabe que está asociado con síndrome de microdeleción 2 q37. Actualmente, se ha propuesto a la mutación de HDAC4 (histona deacetilasa 4) como la causante de la mayoría de las características del síndrome de microdeleción 2q37 (14). Estas mutaciones de HDAC4 se han asociado fuertemente con trastornos del sueño que incluyen múltiples despertares durante la noche en la infancia y episodios prolongados de sueño ininterrumpido en la edad adulta con ausencia total de sueño.

Específicamente, este gen se encontró en el análisis de redes de interacción junto a 37 genes asociados tanto a la duplicación como aquellos reportados para la microdeleción. Se ha reportado que muchas personas afectadas sin microdeleciones tuvieron una mutación inactivante de HDAC4, un gen en la región eliminada 2q37, lo que llevó a la propuesta de que la mutación de este gen puede ser causante de las características sindrómicas de la microdeleción 2q37 (15).

HDAC4 es un gen en 2q37.3, cuya localización genómica se designa como 239,969,864-240,323,348, fundamental para el desarrollo adecuado de los huesos y de los cartílagos, así como para el desarrollo adecuado del corazón (16). También actúa en la supervivencia de las células nerviosas y juega un papel importante en el desarrollo de trastornos de la conducta, las crisis y la discapacidad intelectual. Probablemente, un desorden en los cromosomas que interfieren con la expresión de este gen, aunque no lo elimina por completo, pueden causar leves síntomas del síndrome de la deleción 2 q37. Sin embargo, los factores que interfieren con el HDAC4 aún no han sido completamente explicados. 
Desconcertantemente, algunas personas pueden no tener el HDAC4 (y otros genes candidatos), pero no tienen ninguno o sólo algunos de los síntomas esperados $(14,16)$.

Por otro lado, estudios realizados en 2017 por Tomita, en los cuales evaluaron los niveles de metilación del ADN en regiones promotoras asociadas con nueve genes circadianos (PER1, PER2, PER3, cryptochrome 1 y 2 , CLOCK, BMALI), revelaron que la mayor frecuencia de metilación de la isla $\mathrm{CpG}$ del promotor asociado con el gen circadiano está presente en pacientes con retrasos psicomotores $y$, específicamente, aquellos afectados por la deleción 2q37 (17).

Los resultados obtenidos en nuestro estudio mostraron una alteración en uno de los genes asociados con afecciones en el sueño (gen PER2), el cual se expresa en un patrón circadiano en el núcleo supraquiasmático, lo que corresponde con los hallazgos encontrados en la literatura del tema.

Finalmente, en 2018, estudios realizados por Correa y sus colaboradores reportaron un paciente masculino de 16 años con evidencia de retraso en el desarrollo, discapacidad intelectual grave y una dismorfia facial, por lo cual el paciente depende de la atención de sus padres (18). Este paciente presenta, dos alteraciones cromosómicas terminales: una duplicación de $14.7 \mathrm{Mb}$ de un segmento del brazo corto del cromosoma 2 (2p25.3p24.3) y una deleción de $4 \mathrm{Mb}$ en el brazo largo del cromosoma 4 (4q35.1q35.2). La presencia de dos modificaciones en el número de copias del terminal sugirió una translocación desequilibrada, que fue validada por FISH en metafases.

\section{Conclusión}

El uso de herramientas diagnósticas, como la hibridación genómica comparativa, se ha posicionado como la tecnología de elección para analizar la cantidad y estructura de los cromosomas, comparándolo con uno de referencia, ya que tiene mayor rendimiento diagnóstico que el cariotipo convencional y mayor sensibilidad y especificidad. Esto ha permitido identificar un número creciente de síndromes asociados con microduplicación o microdeleción. Por lo que podría llegar a ser la prueba de primera categoría para el análisis cromosómico en los próximos años.

El estudio molecular evidenció la duplicación patogénica en 2p25.3p24.3 y la deleción patogénica en 2 q37.3, ambas anteriormente reportadas por separado. El fenotipo de la persona está en consonancia con los de la literatura existente para los síndromes de duplicación y deleción; sin embargo, esta es la primera vez que se reporta este tipo particular de reordenamiento cromosómico.

Las redes de interacción de genes afectados que otorgan el fenotipo de la paciente son importantes, ya que permiten determinar, en conjunto, las características sindrómicas causantes de la patología, además de brindar un acercamiento oportuno a la presentación clínica y molecular determinada en este estudio.

A pesar de tratarse de un ordenamiento no reportado, existe una correlación del diagnóstico clínico de la paciente con la duplicación/deleción encontrada en el estudio molecular, pues ambas, al considerarse patogénicas, llevan al paciente a sufrir las graves consecuencias de la enfermedad.

El conocimiento del genotipo, el endotipo y la expresión fenotípica de los pacientes permite acercarse a una medicina personalizada, basada en el diagnóstico precoz, tratamiento oportuno y reporte de nuevos casos y variantes genéticas, a fin de contribuir a la medicina de precisión que necesitamos para proveer un cuidado de calidad a los pacientes, su familia y la sociedad.

\section{Referencias}

1. Zerbino D, Achuthan P, Akanni W, Amode R, Barrell D, Bhai J et al. Ensembl 2018. Nucleic Acids Res. 2018; 46(D1):D754-61.

2. Corredor A, Hernández- Rodríguez MJ, Martinez-Villanueva J, Muñoz-Calvo MT, Argente J. Severe low growth and 2q37 syndrome. An Pediatric (Barc). 2016; 84(2):116-7.

3. Sperry E, Schuatte, Martin D. Duplication 2p25 in a child with clinical features of CHARGE syndrome. Am J Med Genet A. 2016; 170A(5):1148-54.

4. Genetic Home Reference (GHR). 2q37 deletion síndrome [Internet]; 2018 [acceso: 12 de septiembre de 2018] U.S Department of Health \& Human 
Services. Disponible en: https:/ghr.nlm.nih.gov/ condition/2q37-deletion-syndrome\#synonyms

5. Doherty ES, Lacbawan FL. 2q37 microdeletion syndrome. GeneReviews. Seatle: University of Washington, Seattle; 2013.

6. Genetic and Rare Diseases Information Center (GARD). Síndrome de Microdeleción 2q37 [Internet]. 2013 [Consultado el 12 de septiembre de 2018]. Disponible en https://rarediseases.info.nih.gov/ espanol/13267/sindrome-de-microdelecion-2q37

7. Martínez-Juárez A, Uribe-Figueroa L, Quintana-Palma M, Razo-Aguilera G, Sevilla-Montoya R. Pure trisomy $2 \mathrm{p}$ syndrome in two siblings with an unbalanced translocation and minimal terminal 12q monosomy characterized by high-density microarray. Cytogenet Genome Res. 2014; 142(4):249-54.

8. Buizer-Voskamp JE, Muntjewerff JW, Strengman E, Sabatti C, Stefansson H, Vorstman JA. Genome-wide analysis shows increased frequency of copy number variation deletions in dutch schizophrenia patients. Biol Psychiatry. 2011; 70(7):655-62.

9. Vrijenhoek T, Buizer-Voskamp J, van der Stelt I, Strengman E, Sabatti C, Geurts van Kessel A. Recurrent CNVs disrupt three candidate genes in schizophrenia patients. Am J Hum Genet. 2008; 83(4): 504-10.

10. Addington AM, Rapoport JL. The genetics of childhood-onset schizophrenia: When madness strikes the prepubescent. Curr Psychiatry Rep. 2009; 11(2):156-61.

11. Lee Y, Mattai A, Long R, Rapoport JL, Gogtay N, Addington A. Microduplications disrupting the MYT1L gene (2p25.3). Psychiatr Genet. 2012; 22(4):206-9.

12. Jacquemont ML, Sanlaville D, Redon R, Raoul O, Cormier-Daire V, Lyonnet $S$ et al. Array-based comparative genomic hybridisation identifies high frequency of cryptic chromosomal rearrangements in patients with syndromic autism spectrum disorders. J Med Genet. 2006; 43(11):843-9.
13. Lacbawan F, Jones M, Dutra A, Chandrasekharappa S, Doherty ES. Chromosome 2q37 deletion syndrome: Defining clinical features. Abstract 869. New Orleans [LA]: American Society of Human Genetics Annual Meeting; 2006.

14. Villavicienco-Lorini. Phenotypic variant of brachydactyly-mental retardation syndrome in a family with an inherited interstitial 2q37.3 microdeletion including HDAC4. European Journal of Human Genetics. 2013; 21(7): 743-748.

15. Robinson SW, Morris CD, Goldmuntz E, Reller MD, Jones MA, Steiner RD, Maslen CL. Missense mutations in CRELD1 are associated with cardiac atrioventricular septal defects. Am J Hum Genet 2003; 72:1047.

16. Williams A. Haploinsufficiency of HDAC4 causes brachydactyly mental retardation syndrome, with brachydactyly type e, developmental delays, and behavioral problems. American Journal of Human Genetics. 2010; 87:219-28.

17. Tomita T, Kurita R, Onishi Y. Epigenetic regulation of the circadian clock: Role of 5-aza-2'-deoxycitidine. Biosci Rep. 2017; 37(3): BSR20170053.

18. Correa FA, Jorge AA, Nakaguma M, Canton AP, Costa SS, Funari MF, Mendonca BB. Pathogenic copy number variants in patients with congenital hypopituitarism associated with complex phenotypes. Clinical Endocrinology, 2018; 88(3):425-31. 